\title{
Techno(Stress) and Techno(Distress): Validation of a Specific TechnoStressors Index (TSI) Among Quebec Lawyers
}

\author{
Nathalie Cadieux \\ Business school at \\ Université de Sherbrooke \\ nathalie.cadieux@usherbrooke.ca jean.cadieux@usherbrooke.ca
}

\author{
Nancy Youssef \\ Business school at \\ Université de Sherbrooke \\ nancy.youssef@usherbrooke.ca
}

\begin{abstract}
The pervasive and ubiquitous characteristics of information technology has been associated to technostress. Current measures oftechnostress do not consider some recent issues of the stress generated by technology in the day-to-day work of lawyers. This paper presents the validation of a 25-item self-report scale (TechnoStressors-Index-TSI) for the study of technostress in lawyers' professional context. Items were constructed through qualitative exploratory interviews $(N=22)$ and adaptation of existing scales. The scale was tested $(N=40)$ and retested $(N=2027)$ among Quebec lawyers using EFA and CFA. This scale proposes a second order reflexive model of five dimensions to understand technostress. The scale validation among a large sample of professionals helped to fulfill the gap regarding specific technostressors to which lawyers are exposed and leading to technostress at work or other health outcomes, such as psychological distress. For further research, it needs to be validated with other professionals to confirm its relevance in different contexts.
\end{abstract}

\section{Introduction}

Over the last century, technological developments profoundly transformed the nature of work and work organisation. The digital transformation of work is not a new topic, but in the $4^{\text {th }}$ Industrial Revolution context, the pace of this transformation requires a constant adaptation for organisations and for workers [1]. The pervasive and ubiquitous characteristics of information technology, artificial intelligence, automation, collaborative robotics and digital tools (e.g. tablet, smartphone, etc.) press organizations to revisit and adapt their process and business models but also compel workers to often change their working methods [2].
Although technology helped to improve work flexibility (e.g. by facilitating telework), while increasing productivity, more and more studies are concerned about the dark side of technology [3]. Among the detrimental effects there is "technostress"[4, 5] leading to various health outcomes, such as psychological distress at work, depression or burnout [6]. For professionals working in the knowledge economy, technostress adds to the already highly stressful working environments, making it harder to take one's mind off work.

This is particularly true for lawyers [7, 8] as current contextual factors make lawyers a relevant sample of professionals when it comes to gaining a deep understanding of technostress and its impacts. First, the technological developments of recent decades have considerably transformed the practice of law and contact with clients, as confirmed in a recent qualitative study about technostress among Quebec lawyers [7]. On one side, this population is exposed to a number of "more traditional" technostressors [9, 10] or technostress creators [11] such as work-overload, work-home conflict, invasion of privacy, role ambiguity [7]. On the other side, this population is also exposed to new technostressors, less explored in current measures [9$11]$ : the increased pace of work, the misinformation of clients on the Web and the threat of being eventually replaced by a robot with the emergence of AI [7]. When client consult a professional, they are convinced that they have found the solution to their problems on the Web and they confront the professional, even if the information is wrong. In this context, professionals have to establish their credibility and deconstruct their clients' preconceived ideas [7]. In addition, clients who have embraced these technologies in recent years expect their lawyers to be more responsive. If they send an email and their lawyer does not respond within the hour, they will send it again, seeking to receive an immediate answer. This pressure from clients due to the usability features of ICT [10] increases the pace of work for lawyers. [7]. Moreover, the Canadian government is 
investing in research programs to capitalize on the development of AI and "robot lawyers" in the law sector [12]. These developments, beyond their positive effects on productivity, may also represent a threat for professionals who fear that they will have to modify their work organization in the coming years and are afraid of losing their jobs [1].

These specific challenges entails the need to develop more specific measures on technostressors [13]. As some researchers highlighted, findings on technostress should not be generalized [13, 14] because the use of ICTs varies across professions [13]. Besides, researches on specific measures of technostressors can lead to interesting statements [13].

Despite many research efforts and progress made about technostress in recent years [9-11], much remains to be done [15]. First, more multi-method studies are needed [16] to validate the different dimensions [15] but also to develop new dimensions and thus strengthen the factorial structure of current measurements [15]. Second, current measures do not address some recent professional context issues regarding $\mathrm{AI}$ and the impact of clients' misinformation associated with the weak validity of the information found on the Web for these professional lawyers. This paper aims to bridge this knowledge gap and overcome these limitations by validating a technostressors scale developed with a sample of Quebec lawyers.

\section{Theoretical background}

\subsection{Stress and transactional theory}

Over the years, several authors worked to understand the process by which psychosocial risks (stressors) lead to stress and to various health outcomes such as psychological distress at work, depression, anxiety and burnout [17-23].

Modern approach to stress, transaction-based theory, or transactional theory [20, 24, 25], specify the process by which stressors lead to stress and generate different health outcomes [17, 20].

For these authors, stress is the result of a "transaction" between the individual and his/her environment. A transaction influenced by the individual's adjustment strategies, coping skills and situational factors [9, 20, 24, 25].

\subsection{From stress to technostress}

Technostress [4] can be defined as the stress generated from the use of information and communication technologies (ICTs) [6, 9, 10, 16]. This phenomenon is also defined as all negative effects, direct or indirect, caused by the use of ICTs, on attitudes, behaviors or psychological health of individuals [5, 9, 26]. This definition is also consistent with the transaction-based theory for which stress is the result of a "transaction" between an individual and his/her environment [20, 24, 25]. In this context, technostress is the result of an imbalance between the resources available to the individual and the technostressors to which s/he is exposed, an imbalance potentially leading to health outcomes such as psychological distress, burnout or depression [6].

Ayyagari, Grover and Purvis defined three main characteristics of ICTs, making them potentially harmful to health [10]. These characteristics refer to usability, intrusive and dynamic features of technology. Usability features refer to the usefulness, complexity and reliability of ICTs, which influence their adoption but can also increase an individual's workload [10]. Intrusive features refer to the constant connectivity induced by ICTs, and specifically to presenteeism and anonymity. Presenteeism is directly related to the fact that these technologies make people more reachable outside working hours using laptops, cellphones, the Internet, and so on [27]. The use of these collaborative technologies exposes individuals to various problems related to anonymity [10]. Dynamic features of ICTs refer to the constant and rapid changes that emerge in these technologies. These changes require constant adaptation, which can have an impact on an individual's workload [10]. According to authors, these characteristics generate techno-stressors such as workhome conflict, the intrusion of privacy, role conflict or role ambiguity, work overload and job insecurity [10]. Many studies established a direct link between technostressors and health outcomes [6].

\subsection{Toward a specific technostressor measure, conceptual gaps and aims of this study}

In recent years, the scales used to measure technostressors have evolved significantly [9-11]. As pointed out by Hudiburg himself [28], who contributed to the development of measures on technotress [29], some technologies, when they emerge, can constitute a significant source of stress (technostress), hence the importance of referring to specific technologies in technostress measurement, but also of constantly updating existing measures [15]. In addition, despite this construct's evolution [6], recent studies are still critical about the content of their items [15], particularly with regard to their integration capacity in some existing models [9], which had a significant influence in the development of measures of technostressors [15]. 
Consequently, the development of new dimensions in the understanding of technostress is important on two levels. At the first level, these new dimensions are necessary to better understand technostress, and thus advance current frameworks. At a second level, the development of these new dimensions and associated indicators, when tested in quantitative studies, will confirm or refute the importance of the dimensions included in the constantly evolving measurement scales $[15,16]$. In this context, this study aims to develop a technostressor scale to predict mental health outcomes for lawyers. This aims to confirm the presence of some conceptualized technostressors in the existing literature [9-11], but also to identify new dimensions and new indicators related to these dimensions in order to better understand technostress and predict negative health outcomes related to technology among professional lawyers.

\section{Method}

Consistent with current recommendations in the literature concerning the development of measurement scales [30], the methodology used to develop the TSI proceeded in several successive phases. The first phase consisted in a qualitative exploratory study to identify the techno-stressors to which the professionals are exposed. The second phase resulted in a pre-test with a sample of lawyers to confirm the validity of the items selected for the scale and adjust them as needed. Finally, the third phase involved the validation of the scale with a large sample of regulated professionals by exploratory factor analysis (EFA) and confirmatory factor analysis (CFA). Considering the different methodologies used, this section presents the method for each of these phases.

\subsection{Phase I-Qualitative exploratory study}

3.1.1. Sample and procedures. This first phase is based on qualitative data collected through face-to-face semistructured interviews conducted in 2016 with lawyers in the province of Quebec (Canada). The interview questions used for the data collection consisted of five blocks of open-ended questions (14 questions) derived directly from our literature review, as well as a pre-test conducted at the start of the data collection, which allowed us to adjust the content of the interview guide. Twenty-two (22) participants were involved in this study. They included women (14) and men (8) from Quebec bar associations who were self-employed, associates or employees, working in the private (15) and public (7) sectors, with an average of 16.3 year practice in various fields. The main criteria for inclusion were to be practicing law and to have been a member of the Quebec Bar for at least 12 months. To ensure the heterogeneity of the sample, no more than two lawyers representing the same firm could participate in the study. The total number of participants was determined when empirical and theoretical saturation was reached [31-34]. The participants' average age was 43 and they were working between 40 and 80 hours per week (average of 54 hours/week).

3.1.2 Data analysis. The semi-structured interviews were recorded and then fully transcribed. A thematic content analysis of the interviews with a semi-inductive qualitative approach was performed using QDA Miner 4. The coding process was performed as the data were collected, making it possible to determine when theoretical and empirical saturation had been reached [31]. The analysis took place in 5 phases based on the work of Creswell [35]. However, given the semiinductive research approach used, the coding was based on a list of ICTs' characteristics, techno-stressors and symptoms of psychological distress drawn from the literature review, which was then enriched during the coding process. This analytic strategy was carried out iteratively [36]. Each step was repeated until the typology stabilized, that is, until no new interviews produced new or relevant data regarding the categories. The categories were well developed and the relationships between the categories had been thoroughly validated, thus confirming that theoretical and empirical saturation had been reached [37, 38]. A diary and codebook were also kept throughout the data collection process. To ensure the internal validity of the research, a randomly selected interview sample was coded by two different researchers, including an expert, and then subjected to multiple coding. Through comparison and discussion, multiple coding provides a common and unambiguous view of the meaning of codes between two researchers, ensuring consistency in the data and codes [31]. This type of coding makes it possible to obtain clearer code definitions and leads to better reliability. The transcripts were then carefully coded a second time by the other researcher, and the final codes were compared and classified [36]. The coding process and final coding of the transcripts were validated by an expert to ensure their credibility. Finally, to confirm the validity of the conclusions reached, the results of the analyses were presented to three different lawyer focus groups from different practice settings who had not participated in the study. This first phase, combined with the use of existing scales, allowed the creation of a preliminary scale consisting of 32 items classified under 9 dimensions. Table 1 presents a synthesis of items' sources of the preliminary scale for pre-test. 
Table 1. Synthesis of items' sources of the preliminary scale for pre-test.

\begin{tabular}{|c|c|c|}
\hline Dimensions & Items & Source \\
\hline $\begin{array}{l}\text { Feeling of role } \\
\text { overload }\end{array}$ & $\begin{array}{c}4 \\
\text { items }\end{array}$ & $\begin{array}{l}\text { Adaptation of Taradaftar et al. } \\
\text { (2007) [39] and French validation } \\
\text { by Loup (2016) [40] }\end{array}$ \\
\hline $\begin{array}{l}\text { Feeling of } \\
\text { informational } \\
\text { overload }\end{array}$ & $\begin{array}{c}3 \\
\text { items }\end{array}$ & $\begin{array}{l}\text { Adaptation of Karr-Wisniewski } \\
\text { and Lu [41] and French validation } \\
\text { by Loup (2016) [40]. }\end{array}$ \\
\hline $\begin{array}{l}\text { Feeling of } \\
\text { communicatio } \\
\text { n overload } \\
\end{array}$ & $\begin{array}{c}3 \\
\text { items }\end{array}$ & $\begin{array}{l}\text { Adaptation of Karr-Wisniewski } \\
\text { and Lu [41]and French validation } \\
\text { by Loup (2016) [40]. }\end{array}$ \\
\hline $\begin{array}{l}\text { Feeling of life } \\
\text { intrusiveness }\end{array}$ & $\begin{array}{c}6 \\
\text { items }\end{array}$ & $\begin{array}{l}\text { Adaptation of Ayyagari et al. } \\
\text { (2011) [10], and French validation } \\
\text { by Loup (2016) [40]. }\end{array}$ \\
\hline $\begin{array}{l}\text { Feeling of } \\
\text { pressure } \\
\text { resulting from } \\
\text { ICTs } \\
\end{array}$ & $\begin{array}{c}4 \\
\text { items }\end{array}$ & $\begin{array}{l}\text { Adaptation of Harris (2011) [42] } \\
\text { and French validation by Loup } \\
(2016)[40] \text {. }\end{array}$ \\
\hline $\begin{array}{l}\text { Feeling of } \\
\text { utility }\end{array}$ & $\begin{array}{c}4 \\
\text { items }\end{array}$ & $\begin{array}{l}\text { Adaptation of Ayyagari et al. } \\
\text { (2011) [10]and French validation } \\
\text { by Loup (2016) [40]. }\end{array}$ \\
\hline $\begin{array}{l}\text { Feeling of } \\
\text { misinformatio } \\
\text { n }\end{array}$ & $\begin{array}{c}3 \\
\text { items }\end{array}$ & New items emerged from phase I \\
\hline $\begin{array}{l}\text { Feeling of } \\
\text { insecurity due } \\
\text { to AI }\end{array}$ & $\begin{array}{c}4 \\
\text { items }\end{array}$ & New items emerged from phase I \\
\hline $\begin{array}{l}\text { Feeling of } \\
\text { competency }\end{array}$ & $\begin{array}{c}2 \\
\text { items }\end{array}$ & New items emerged from phase I \\
\hline
\end{tabular}

\subsection{Phase II - Pre-test}

3.2.1. Sample and procedures. To validate all items, a pre-test was conducted with a sample of 40 lawyers. The participants' average age was 39.93. 13 participants were working in the private sector (self-employed, employed or associate), 13 in the public or parapublic service (e.g. ministry) and 14 in companies (e.g. private, non-profit, professional association). There were 25 women and 15 men. The sample consisted of lawyers working in various section bars. 10 participants had less than 10 years of practice and 30 more than 10 years of practice. Participants had to complete a selfadministered questionnaire online via a SurveyMonkey link.

3.2.2. Data analysis. For this pre-test, reliability analysis was performed with SPSS. After these analyses, some items were reformulated or removed because of their low impact on overall scale reliability, and for parsimony. The dimension "feeling of competency" was removed due to the very low reliability of its items. At this point, we considered the scale to be multidimensional. The results of the pre-test show a good validity of the scale. The final scale consists of 8 dimensions and 25 items. This adjusted scale is the one used for collecting data from 2,027 lawyers during fall 2018. This scale is presented in Appendix A. The respondents were asked "To what extent do you agree or disagree with the following elements", using an 8-point Likert-type scale to respond to all survey items. The scale ranged from 1 (strongly disagree) to 8 (strongly agree). Scales with more evaluation points provide a much more accurate picture of the variables under study [43], without altering in any way the validity of the instruments [44]. They are also better suited for regression analyses, which are assumed to use numerical variables [45]. Moreover, a scale with an even number of points facilitates the dichotomization of the participant's perception of the problem. Finally, considering that other variables were measured as part of the study, this choice was made to ensure the uniformity of the questionnaire and thus facilitate its completion by participants. The scale in French is the one that has been validated. Appendix A presents the items in the English version to facilitate understanding. It is important to point out that the items in the last two dimensions have never been validated in English since they were developed as part of this research in French.

\subsection{Phase III- Final validation}

3.3.1. Sample and procedures. 1,825 participants were involved in this final validation, including 1,257 women and 568 men. The participants' average age was 41 years (38.1 for women and 43.9 for men). This sample represents 7.16\% of total Quebec lawyers' population. This large sample is representative of the different Bar sections, as well as the various areas of law practiced in Quebec. Responses were collected through SurveyMonkey between September and October 2018.

3.3.2 Analysis procedure. For this validation phase, exploratory factor analysis (EFA) and confirmatory factor analysis (CFA) were performed. To perform these analyses, the data were splitted randomly in two. One set of data (908 participants) was used for the exploratory factor analysis (EFA) (Principal axis factoring method with a Varimax rotation) (Hinkin, 1998) with SPSS. This analysis confirms the multidimensional measurement model of technostressors related to technostress. The second set of data (917 participants) was used to performed confirmatory factor analysis (CFA) with AMOS.

\section{Results}

\subsection{Exploratory Factor Analysis (EFA)}


Results of EFA illustrate the presence of a structure divided into 5 factors with eigenvalues greater than unity [45]. These factors explained $65.622 \%$ of the common variance and the Scree plot, based on the total variance, also suggests that a representation with five factors is appropriate [45]. Table 2 presents a summary of the reliability analysis produced by SPSS 25 for the 5 subscales of the TSI. For the validation of a new scale, Hair et al. (1998) recommends that communalities be greater than 0.5 , factor loading be greater than 0.30 , the inter-item correlations exceed 0.30 , with a Cronbachs' alpha greater than 0.7 [46]. Except for a question in the dimension "Feeling of misinformation", which has been removed, all items respect the proposed thresholds.

Table 2. Reliability analysis of the scales

\begin{tabular}{|c|c|c|c|c|c|c|}
\cline { 2 - 7 } \multicolumn{1}{c|}{} & $\begin{array}{c}\text { Number } \\
\text { of Items }\end{array}$ & $\begin{array}{c}\text { Min } \\
\text { Communality }\end{array}$ & $\begin{array}{c}\text { Min } \\
\text { Factor } \\
\text { Loading }\end{array}$ & $\begin{array}{c}\text { Min } \\
\text { Correl. } \\
\text { Inter Items }\end{array}$ & $\begin{array}{c}\text { Alpha } \\
\text { Cronbach }\end{array}$ & $\begin{array}{c}\text { Min Corrected } \\
\text { Item-total } \\
\text { Correl. }\end{array}$ \\
\hline Feeling of overload & 9 & 0.505 & 0.558 & 0.408 & 0.917 & 0.642 \\
\hline Feeling of life intrusiveness & 6 & 0.500 & 0.629 & 0.485 & 0.905 & 0.658 \\
\hline Feeling of utility (reverse) & 3 & 0.698 & 0.824 & 0.725 & 0.909 & 0.787 \\
\hline Feeling of misinformation & $\begin{array}{c}3 \\
\left(2^{*}\right)\end{array}$ & $\begin{array}{c}0.199 \\
\left(0.575^{*}\right)\end{array}$ & $\begin{array}{c}0.199 \\
\left(0.706^{*}\right)\end{array}$ & $\begin{array}{c}0.383 \\
(0.692 *)\end{array}$ & $\begin{array}{c}0.699 \\
\left(0.817^{*}\right)\end{array}$ & $0.313\left(0.692^{*}\right)$ \\
\hline Feeling of insecurity due to AI & 4 & 0.823 & 0.891 & 0.835 & 0.965 & 0.889 \\
\hline
\end{tabular}

\subsection{Confirmatory Factor Analysis (CFA) results}

For this analysis, the second sub-sample of 917 participants was used to CFA performed with AMOS 25. To validate the fit to the data of an EFA resulting from a structural equation, Roussel (2002) proposes to use two measures of absolute fit [47], two incremental fit measures (if possible a type II and a type III [48]) and finally one or two parsimonious measures [47]. Table 3 presents the statistics selected to evaluate the fit of the model, the thresholds as proposed by Roussel (2002) [47] as well as the statistics produced by the structural model.

Table 3. Overall adjustment of the measurement model

\begin{tabular}{|c|c|c|c|}
\hline & $\begin{array}{c}\text { Overall } \\
\text { adjustment }\end{array}$ & Threshold & Statistics \\
\hline $\begin{array}{l}\text { Absolute } \\
\text { fit }\end{array}$ & $\begin{array}{l}\text { Chi-Square } \\
\text { Statistic (df) } \\
\text { GFI } \\
\text { AGFI }\end{array}$ & $\begin{array}{l}\text { P-val<0.05 } \\
>0.9 \\
>0.9\end{array}$ & $\begin{array}{l}X 2(220)= \\
2303,205 ; p- \\
\text { val }=0.000 \\
\text { GFI }=0.804 \\
\text { AGFI }=0.755\end{array}$ \\
\hline $\begin{array}{l}\text { Increment } \\
\text { al fit }\end{array}$ & $\begin{array}{l}\text { TLI (type II) } \\
\text { CFI (Type } \\
\text { III) }\end{array}$ & $\begin{array}{l}>0.9 \\
>0.9\end{array}$ & $\begin{array}{l}\text { TLI }=0.860 \\
\text { CFI }=0.878\end{array}$ \\
\hline Parsimony & PNFI & $\begin{array}{l}\text { Between } 0 \text { and } \\
1 \text {, higher value } \\
\text { indicates } \\
\text { greater } \\
\text { parsimony }\end{array}$ & PNFI $=0.754$ \\
\hline
\end{tabular}

Regarding the Jöreskog's rho, Fornell and Larker (1981) proposed using the same criterion as Cronbach's alpha, which is to exceed the threshold of 0.7 [49].With respect to convergent validity, Fornell and Larker (1981) argue that a construct presents a good convergence validity if the loading factors are all significantly related to the construct to which it refers and if the variance-extracted is higher or equal to 0.5 . [49]. As shown in Table 4, all scales respect these thresholds.

Table 4. Reliability analysis

\begin{tabular}{|l|l|l|l|}
\cline { 2 - 4 } \multicolumn{1}{c|}{} & $\begin{array}{c}\text { \# of } \\
\text { items }\end{array}$ & $\begin{array}{c}\text { Variance } \\
\text { extracted } \\
(>.50)\end{array}$ & $\begin{array}{c}\text { Jöreskog's } \\
\text { Rho }\end{array}$ \\
\hline $\begin{array}{l}\text { Feeling of } \\
\text { overload }\end{array}$ & 9 & 0.539 & 0.913 \\
\hline $\begin{array}{l}\text { Feeling of life } \\
\text { intrusiveness }\end{array}$ & 6 & 0.641 & 0.915 \\
\hline Feeling of utility & 3 & 0.760 & 0.907 \\
\hline $\begin{array}{l}\text { Feeling of } \\
\text { misinformation }\end{array}$ & 2 & 0.751 & 0.857 \\
\hline $\begin{array}{l}\text { Feeling of } \\
\text { insecurity due to } \\
\text { AI }\end{array}$ & 4 & 0.871 & 0.964 \\
\hline
\end{tabular}

Finally, with respect to the discriminant validity, good constructs should share more variance with their own observable variables than with other constructs. The square correlation between two constructs (a, b) must be less than the minimum of the variances of a and b [49]. The fit of the measurement model is slightly lower than the threshold; however the project proposes scales in development. Considering the stage of development of technostress, the adjustment is acceptable. Table 4 presents the reliability analysis of 
each subscale. Table 5 shows the discriminant validity analysis. All constructs are different enough.

Table 5. The discriminant validity

\begin{tabular}{|c|c|c|c|c|c|}
\hline $\mathbf{a}$ & $\mathbf{r}$ & $\mathbf{b}$ & $\mathbf{r}$ & $\mathbf{r}$ & $\begin{array}{c}\text { Min (VEa, } \\
\text { VEb) }\end{array}$ \\
\hline Overload & $<-->$ & Misinfo & 0.294 & 0.086 & 0.539 \\
\hline Overload & $<-->$ & AI & 0.259 & 0.067 & 0.539 \\
\hline Overload & $<-->$ & Intrusive & 0.726 & 0.527 & 0.539 \\
\hline Overload & $<-->$ & Utility & 0.277 & 0.077 & 0.539 \\
\hline Misinfo & $<-->$ & AI & 0.247 & 0.061 & 0.751 \\
\hline Misinfo & $<-->$ & Intrusive & 0.252 & 0.064 & 0.641 \\
\hline Misinfo & $<-->$ & Utility & 0.044 & 0.002 & 0.751 \\
\hline AI & $<-->$ & Intrusive & 0.204 & 0.042 & 0.641 \\
\hline AI & $<-->$ & Utility & 0.007 & 0.000 & 0.764 \\
\hline Intrusive & $<-->$ & Utility & 0.095 & 0.009 & 0.641 \\
\hline
\end{tabular}

Figure 1 shows the second order reflexive model that represents the technostress concept. A Heywood case was found. Indeed, e25 shows a slightly negative variance. Hair et al. recommend to set the variance to 0.005 and rerun the analysis [46].

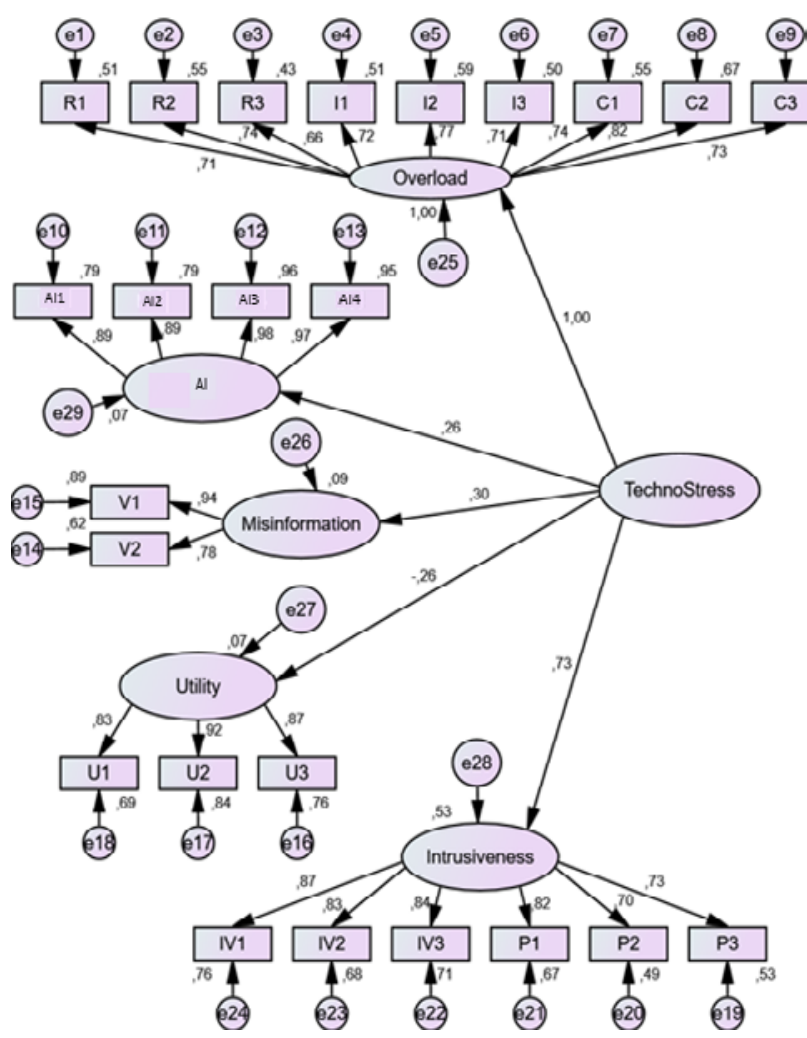

Figure 1. Second order reflexive model
Table 6 shows the overall adjustment for the second order reflexive model of our technostress concept. In the context of new scale development, the statistics are low but acceptable and in the same range of the CFA model. All paths between the technostress and its first order constructs were highly significant. Regarding the nomological validity, we propose to study the correlation of TSI with Kessler's psychological distress scale (K6) [50]. K6 scale measures with 6 questions on a Likert scale (0 to 4 ) how often, during the last month, the person felt nervous, desperate, agitated, so depressed that nothing could make her/him smile, had the impression that everything required an effort and finally had the feeling of being good at nothing. For each question, respondents had to choose a given score from 0 (never) to always (4). The maximum score of the sum is 24 and the higher the score, the higher the psychological distress. From our data, the Jöreskog's rho $=0.903$ for the Kessler scale. The analysis shows a positive significant medium effect size (standardized beta $=0.38)$. The technostress explains $r^{2}=14 \%$ of the variance of the Kessler scale [50].

Table 6. Overall adjustment of the second order reflexive model of technostress

\begin{tabular}{|c|c|c|c|}
\hline & $\begin{array}{l}\begin{array}{l}\text { Overall } \\
\text { adjustment }\end{array} \\
\end{array}$ & Threshold & Statistics \\
\hline $\begin{array}{l}\text { Absolute } \\
\text { fit }\end{array}$ & $\begin{array}{l}\text { Chi-Square } \\
\text { Statistic (df) } \\
\text { GFI } \\
\text { AGFI }\end{array}$ & $\begin{array}{l}\text { P-val }<0.05 \\
>0.9 \\
>0.9\end{array}$ & $\begin{array}{l}X 2(248)= \\
2579.427 ; p- \\
\text { val }=0.000 \\
\text { GFI }=0.794 \\
\text { AGFI }=0.751\end{array}$ \\
\hline $\begin{array}{l}\text { Increment } \\
\text { al fit }\end{array}$ & $\begin{array}{l}\text { TLI (type II) } \\
\text { CFI (Type } \\
\text { III) }\end{array}$ & $\begin{array}{l}>0.9 \\
>0.9\end{array}$ & $\begin{array}{l}\text { TLI }=0.857 \\
\text { CFI }=0.871\end{array}$ \\
\hline Parsimony & PNFI & $\begin{array}{l}\text { Between } 0 \text { and } \\
1 \text {, higher value } \\
\text { indicates } \\
\text { greater } \\
\text { parsimony }\end{array}$ & PNFI $=0.773$ \\
\hline
\end{tabular}

\section{Discussion and contributions}

This study aimed to bridge the knowledge gap about the measurement of technostress in professional context and enrich the traditional dimensions and items used to measure technostress. This, in order to reflect the impact of some techno-stressors that lawyers are facing and that are not currently included in existing framework [6, 911]. The size of the coefficients (as shown in figure 1) suggests that technostress is heavily a question of overload feeling and life intrusiveness feeling. The other facets of technostress are significant but to a lesser extent. Concretely, the more stressful is technology, the 
less is the utility feeling; and the higher is the misinformation feeling, the more is the feeling of insecurity due to AI. Despite this progress, the model fit is slightly below the proposed thresholds [47]. It should also be noted that in the final scale, clients' misinformation is only measured using 2 items. This situation is not optimal in the context of structural equation modeling methods. Other researches, qualitative and quantitative, should be carried out to better understand the content of this dimension, and possibly enrich this or others dimensions in order to improve the predictive capacity of the scale. It should also be noted that the EFA analysis of this population suggested that all items related to overload should be grouped into a single latent variable. This is not surprising, however, considering the results obtained in the context of this research project, which tends to show that lawyers are overexposed to stress and work overload. Although this result is contrary to the one in the literature, which separates the overload into several dimensions [10], several hypotheses can be put forward to explain this result.

First, it is possible that overload (related to role, information and communication) may be exacerbated by an already very, very intense overload in the lawyers workplace context [8]. This would explain why, mathematically, a set of correlations are suddenly synchronized, forcing their matching into a single latent variable.

Second, as shown by recent conceptual developments in technostress [7], ICTs' characteristics, including usability feature et intrusive feature tend to create a zone of permeability between stressors from different spheres of life, while exacerbating stressors already present in the workplace [7]. As a result, this increased permeability, as well as the greater feeling of overload generated by technological characteristics, could increase the pressure on technostressors (e.g., a feeling of overload related to technology) who in turn increase technostress. Although leading to a loss of precision in the analysis regarding the mechanisms underlying this overload, these results raise new avenues for research, particularly regarding the relationships between certain technostressors and other stressors already present in the workplace (e. g. work overload) in order to pursue conceptual development [6, $9,10]$. These results also highlight the importance of focusing on the synchronicity of technostress with other issues in an environment [9] already overexposed to stress-related problems (psychological distress, burnout, etc.) [8]. Beyond these conclusions, it is important to highlight the theoretical and practical contributions of this paper.

\subsection{Theoretical contributions}

Firstly, the validation of this scale on technostress, while reinforcing some indicators developed and validated by previous research $[9,10,41,42,51]$, allowed to overcome the actual dimensions of technostress creator/technostressor [9\{Ayyagari, 2011 $\# 29,10,11]$. On one side, the study confirms the importance of some technostressor categories, such as the techno-overload (feeling of overload) [52], technoinvasion (feeling of intrusiveness) [9, 10] and utility (feeling of utility) [10]. On the other side, this paper bridges a knowledge gap by developing new indicators and specific categories of techno-stressors facing lawyers working in the knowledge-based economy. Particularly in what pertains to the impact of clients' misinformation (feeling of misinformation) and the feeling of insecurity generated by AI for these professionals. This confirms that certain technologies, when they emerge in a workplace, can be a significant source of technostress [29] and highlighted the importance of referring to specific technologies when measuring technostress, but also of constantly updating existing measures [15]. Considering that the use of ICTs varies across professions [13] and that some studies argue in favour of developing studies based on specific professions, this study is a step in this direction.

Secondly, the present scale, using various research methods (qualitative and quantitative), identified more precisely the different dimensions of the technostress by grouping the different indicators under 5 main dimensions. This contribution will eventually facilitate research on the development of theoretical models aimed at understanding the mechanisms by which technostressors lead to different health outcomes. In this context, the proposed scale was validated as a predictor of psychological distress [50], but the scale should eventually be tested with other health outcomes, such as burnout or depression, and other professions.

Thirdly, the results highlighted the respective contribution of the dimensions of technostress, while some of the dimensions (such as the feeling of overload) have a preponderant weight in the explanation of technostress. This observation should be taken into account to improve the measures of technostress, but also in the understanding of its underlying mechanisms.

\subsection{Practical contributions}

Empirically, the development of this new scale identified the contribution of new techno-stressors emanating from the practice of a profession in the knowledge economy context. These technostressors should now be considered by several actors. Firstly, as the results showed, insecurity generated by the use of AI in the context of law practice seems to contribute to the 
explanation of technostress. Consequently, organizations using AI should not minimize this impact as this technostressor adds to the stress already present in professionals' highly stressful environments. These findings argue for management practices in the workplace to support professionals [9, 13] in the implementation of AI, including better communication to reduce the anxiety generated by these changes. These communication efforts should be accompanied by an indepth reflection about the consequences of AI on work organization, to minimize impacts for the professionals. Secondly, several avenues have to be considered regarding the impact of clients' misinformation from the web. Thus, a public awareness campaign should be carried out to raise awareness about poor quality of information on the web. It would facilitate the work of professionals to deconstruct their clients' preconceived ideas. Finally, training of professionals regarding the interaction with clients could facilitate their day-to-day work.

\section{Conclusion and limitations}

Results highlight the importance of developing new measures and scales of technostressors adapted to the context of the knowledge-based economy. Despite the contributions mentioned above, the results must be interpreted within certain limits. Firstly, this new scale was only validated in the profession of lawyers. Secondly, the self-reported scale is a subjective assessment of the phenomenon by the participants. Thirdly, regarding the nomological validity, the new scale was only validated with psychological distress scale, a single health outcome. Fourthly, some items of the scale were removed through the validation process, resulting in the fact that feeling of clients' misinformation is only measured by 2 items. However, using only two items to measure a dimension when using the structural equations is not optimal and generates mostly negative variances. This weakness forced to use a Heywood case. In this context, Hair recommends that researchers eventually test the model on other data to study model generalization and improvement [46]. Finally, the data related to the model fit show that the fit of the measurement model is slightly below the thresholds [47]. However, the paper proposes new subscale development, which possibly explains these results. Despite these limitations, this scale, validated with a large sample of lawyers, is a primary effort to conceptualize and measure specific technostressors related to professional context. In this instance, the TSI addresses a knowledge gap by identifying new categories of technostressors as well as specific items to these categories to understand the technostress related to emergent technologies, such as $\mathrm{AI}$, in the knowledge-based economy context.

\section{References}

[1] E. Brynjolfsson, and A. McAfee, The second machine age: Work, progress, and prosperity in a time of brilliant technologies: WW Norton \& Company, 2014.

[2] W. M. Foster, J. S. Hassard, J. Morris, and J. Wolfram Cox, "The changing nature of managerial work: The effects of corporate restructuring on management jobs and careers," Human Relations, vol. 72, no. 3, pp. 473-504, 2019.

[3] P. Holland, and A. Bardoel, "The impact of technology on work in the twenty-first century: exploring the smart and dark side," Taylor \& Francis, 2016.

[4] C. Brod, "Managing technostress: optimizing the use of computer technology," Personnel Journal, vol. 61, no. 10, pp. 753-57, 1982.

[5] M. M. Weil, and L. D. Rosen, Technostress: Coping with technology@work@home@play: Wiley New York, 1997.

[6] M. Tarafdar, C. L. Cooper, and J. F. Stich, "The technostress trifecta-techno eustress, techno distress and design: Theoretical directions and an agenda for research," Information Systems Journal, vol. 29, no. 1, pp. 6-42, 2019.

[7] N. Cadieux, E. Mosconi, and N. Youssef, "ICT, Permeability Between the Spheres of Life and Psychological Distress Among Lawyers," in 52nd Hawaii International Conferenceon System Sciences, HawaÏ, Maui, 2019, pp. 6729-6738.

[8] N. Cadieux, J. Cadieux, N. Youssef, M. Gingues, and S.M. Godbout, Rapport de recherche : Étude des déterminants de la santé psychologique au travail chez les avocat(e)s québécois(es), Phase II - 2017-2019., Research report, Université de Sherbrooke, Sherbrooke, 2019.

[9] T. Ragu-Nathan, M. Tarafdar, B. S. Ragu-Nathan, and Q. Tu, "The consequences of technostress for end users in organizations: Conceptual development and empirical validation," Information systems research, vol. 19, no. 4, pp. 417-433, 2008.

[10] R. Ayyagari, V. Grover, and R. Purvis, "Technostress: technological antecedents and implications,” MIS Quarterly, vol. 35, no. 4, pp. 831, Dec 2011.

[11] M. Tarafdar, Q. Tu, T. Ragu-Nathan, and B. S. RaguNathan, "Crossing to the dark side: examining creators, outcomes, and inhibitors of technostress," Communications of the ACM, vol. 54, no. 9, pp. 113-120, 2011.

[12] A. Roy, "Intelligence artificielle : L'ère des robotsavocats," La presse, 2017.

[13] C. Maier, S. Laumer, and A. Eckhardt, "Information technology as daily stressor: pinning down the causes of burnout," Journal of Business Economics, vol. 85, no. 4, pp. 349-387, 2015.

[14] S. D. Pawlowski, E. A. Kaganer, and J. J. Cater III, "Focusing the research agenda on burnout in IT: social representations of burnout in the profession," European journal of information systems, vol. 16, no. 5, pp. 612-627, 2007.

[15] T. Fischer, A. Pehböck, and R. Riedl, "Is the Technostress Creators Inventory Still an Up-To-Date 
Measurement Instrument? Results of a Large-Scale Interview Study," in 14th International Conference on Wirtschaftsinformatik, Siegen, Germany, 2019, pp. 1-12.

[16] T. Fischer, and R. Riedl, "Technostress research: a nurturing ground for measurement pluralism?," Communications of the Association for Information systems, vol. 40, no. 1, pp. 17, 2017.

[17] S. Folkman, "Stress: appraisal and coping," Encyclopedia of behavioral medicine, pp. 1913-1915: Springer, 2013.

[18] D. C. Ganster, "Measurement challenges for studying work-related stressors and strains," Human Resource Management Review, vol. 18, no. 4, pp. 259-270, 2008.

[19] L. I. Pearlin, "Stress and Mental Health: A Conceptual Overview," A Handbook for the Study of Mental Health â€" Social Contexts, Theories, and Systems, A. V. Horwitz and T. L. Schied, eds., pp. 161-175, New York: Cambridge University Press, 1999.

[20] R. S. Lazarus, and S. Folkman, Stress, appraisal, and coping, New York: Springer, 1984.

[21] R. A. Karasek, "Job demands, job decision latitude, and mental strain: implications for job design,” Administrative Science Quarterly, vol. 24, pp. 285-308, 1979.

[22] R. Karasek, and T. Theorell, Healthy Work: Stress, Productivity and the Reconstruction of Working Life, 1990.

[23] J. Siegrist, "Adverse health effects of high effort-low reward conditions," Journal of Occupational Health Psychology, vol. 1, no. 1, pp. 27-41, 1996.

[24] R. S. Lazarus, Psychological stress and the coping process, New York: McGraw-Hill, 1966.

[25] S. Folkman, Stress: appraisal and coping: Springer, 2013.

[26] L. Chen, and A. Muthitacharoen, “An empirical investigation of the consequences of technostress: Evidence from China," Information Resources Management Journal, vol. 29, no. 2, pp. 14-36, 2016.

[27] S. C. Srivastava, S. Chandra, and A. Shirish, "Technostress creators and job outcomes: theorising the moderating influence of personality traits," Information Systems Journal, vol. 25, no. 4, pp. 355-401, Jul 2015.

[28] R. A. Hudiburg, "Psychology of computer use: XVII. The Computer Technology Hassles Scale: Revision, reliability, and some correlates," Psychological Reports, vol. 65, no. 3_suppl2, pp. 1387-1394, 1989.

[29] R. A. Hudiburg, "Psychology of computer use: XXXIV. The Computer Hassles Scale: Subscales, norms, and reliability,”Psychological Reports, vol. 77, no. 3, pp. 779-782, 1995.

[30] T. R. Hinkin, "A review of scale development practices in the study of organizations," Journal of management, vol. 21, no. 5, pp. 967-988, 1995.

[31] M. B. Miles, and A. M. Huberman, Analyse des données qualitatives: De Boeck Supérieur, 2003.

[32] J.-P. Pourtois, and H. Desmet, Épistémologie et instrumentation en sciences humaines: Editions Mardaga, 2007.

[33] J. Saldaña, The coding manual for qualitative researchers: Sage, 2015.

[34] A. L. Strauss, M.-H. Soulet, J. M. Corbin, S. Emery, and M.-H. Soulet, Les fondements de la recherche qualitative: techniques et procédures de développement de la théorie enracinée: Academic Press/Saint-Paul, 2004.

[35] J. W. Creswell, Educational research: Planning, conducting, and evaluating quantitative: Prentice Hall Upper Saddle River, NJ, 2002.

[36] P. Paillé, "L’analyse par théorisation ancrée," Cahiers de recherche sociologique, no. 23, pp. 147-181, 1994.

[37] B. G. Glaser, and A. L. Strauss, Discovery of grounded theory: Strategies for qualitative research: Routledge, 2017.

[38] S. J. Tracy, “Qualitative research methods,” UK: WileyBlackwell, 2013.

[39] M. Tarafdar, Q. Tu, B. S. Ragu-Nathan, and T. S. RaguNathan, "The Impact of Technostress on Role Stress and Productivity," Journal of Management Information Systems, vol. 24, no. 1, pp. 301, Summer 2007.

[40] P. Loup, "Influence des Technologies Nomades sur le bien-être au travail: une lecture par la théorie de la conservation des ressources," Université de Montpellier, Montpellier, 2016.

[41] P. Karr-Wisniewski, and Y. Lu, "When more is too much: Operationalizing technology overload and exploring its impact on knowledge worker productivity," Computers in Human Behavior, vol. 26, no. 5, pp. 1061-1072, 2010.

[42] K. J. Harris, K. Marett, and R. B. Harris, "Technologyrelated pressure and work-family conflict: Main effects and an examination of moderating variables," Journal of Applied Social Psychology, vol. 41, no. 9, pp. 2077-2103, 2011.

[43] R. F. DeVellis, Guidelines in scale development. Scale Development: Theory and Applications, Newbury Park, California: Sage Publications, 1991.

[44] M. S. Matell, and J. Jacoby, "Is There an Optimal Number of Alternatives for Likert Scale Items? Study I: Reliability and Validity," Educational and Psychological Measurement, vol. 31, no. 3, pp. 657-674, 1971.

[45] J. C. Nunnally, and I. H. Bernstein, PsychometricTheory, New York: McGraw-Hill, 1994.

[46] J. Hair, R. Anderson, R. Tatham, and W. Black, Multivariate Data Analysis, Fifth edition ed., New Jersey: Prentice Hall, 1998.

[47] P. Roussel, F. Durrieu, E. Campoy, and A. Akermi, Méthodes d'Equations Structurelles: Recherche et Applications en Gestion, Paris: Economica, 2002.

[48] L.-t. Hu, and P. M. Bentler, "Fit indices in covariance structure modeling: Sensitivity to underparameterized model misspecification," Psychological methods, vol. 3, no. 4, pp. 424-453, 1998.

[49] C. Fornell, and D. Larker, "Structural equation modeling and regression: guidelines for research practice," Journal of Marketing Research, vol. 18, no. 1, pp. 39-50, 1981.

[50] R. C. Kessler, G. Andrews, L. J. Colpe, E. Hiripi, D. K. Mroczek, S.-L. Normand, E. E. Walters, and A. M. Zaslavsky, "Short screening scales to monitor population prevalences and trends in non-specific psychological distress,” Psychological medicine, vol. 32, no. 6, pp. 959-976, 2002.

[51] M. Tarafdar, Q. Tu, B. S. Ragu-Nathan, and T. RaguNathan, "The impact of technostress on role stress and productivity,” Journal of Management Information Systems, vol. 24, no. 1, pp. 301-328, 2007.

[52] M. Tarafdar, Q. Tu, and T. Ragu-Nathan, "Impact of technostress on end-user satisfaction and performance," 
Journal of Management Information Systems, vol. 27, no. 3, pp. 303-334, 2010.

\section{Appendix A. Scale for final phase of validation}

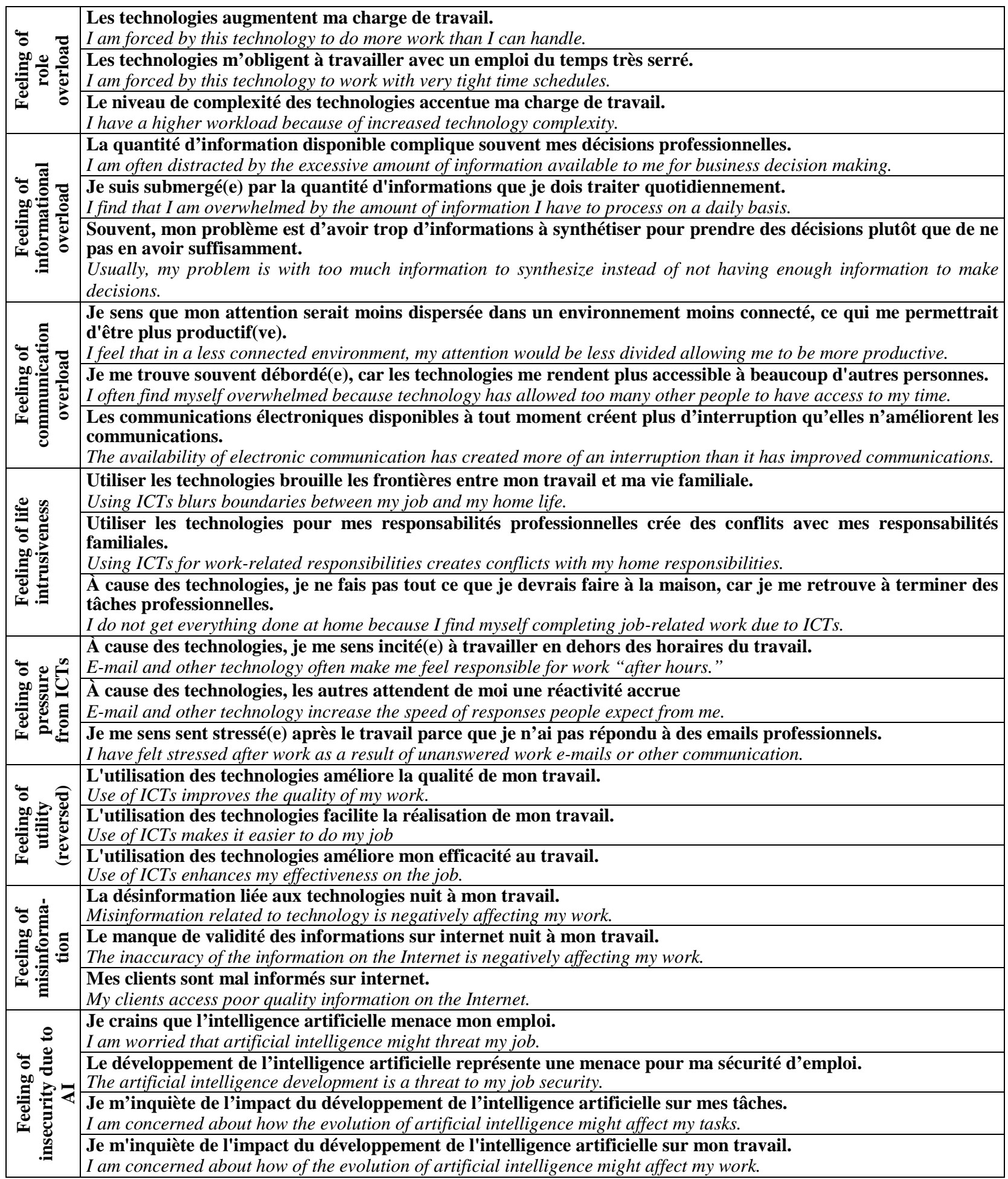

